\title{
Ripening Quality of 'Bartlett' Pears (Pyrus communis L.) Subjected to Phytosanitary X-ray Irradiation Treatment Followed by Simulated Retail Display
}

\author{
Sokrith Sea, Cyril Rakovski, and Anuradha Prakash ${ }^{1}$ \\ Department of Food Science, Chapman University, One University Drive, \\ Orange, CA 92866
}

Additional index words. postharvest, texture, ethylene, respiration, sensory

\begin{abstract}
The objective of this study was to determine the effect of phytosanitary X-ray irradiation on the physicochemical properties and sensory attributes of early- and lateharvest 'Bartlett' pears (Pyrus communis L.) during ripening under simulated commercial conditions. Irradiation delayed ripening, which in turn affected respiration rate, ethylene production, and firmness. Irradiation decreased ethylene production in early- and lateharvest pears and maintained firmness as compared with the control pears. In the earlyharvest pears, irradiation did not affect respiration rate, weight loss, or total soluble solids. However, in the late-harvest pears, irradiation resulted in an increase in respiration rate and weight loss and a decrease in total soluble solids. The appearance for irradiated earlyharvest pears was rated lower by consumers, but there were no significant differences in the rest of the attributes. Consumers rated the irradiated late-harvest pears lower $(P<$ 0.05 ) than the non-treated pears for overall liking, texture, and flavor on a 9-point hedonic scale. Consumers perceived the late-harvest irradiated pears to be less sweet than the control $(P<0.05)$, which correlated with total soluble solids of $12.4 \%$ for treated pears vs. $13.2 \%$ for the control. Our results show that there were significant differences between the early- and late-harvest pears in their responses to irradiation. Although some sensory attributes were negatively affected, the delay in ripening helped reduce bruising and mold development in irradiated pears during the retail display simulation.
\end{abstract}

The United States produced 407,000 t of 'Bartlett' pears (Pyrus communis L.) in 2012 [U.S. Department of Agriculture (USDA), 2013]. California produces $\approx 32 \%$ of all pears in the nation and exports between $20 \%$ and $30 \%$ of the fresh crop each year to Canada, Mexico, Costa Rica, Honduras, Guatemala, Brazil, and eastern Russia (California Pear Advisory Board, Pear Pest Management Research Fund, California Specialty Crops Council, University of California Cooperative Extension, 2011; California Foundation for Agriculture in the Classroom, 2011).

A consequence of globalized trade is the risk of introducing or spreading insect pests; therefore, phytosanitary measures are required to disinfest fresh produce leaving a quarantine area (Hallman, 2011). Common pests that affect pears include the codling moth (Cydia pmonella), pear psylla (Cacopsylla pyricola), eriophyid mites (Acarina: Eriophyidae), and oriental fruit moth (Grapholita molesta)

Received for publication 19 Aug. 2014. Accepted for publication 17 Nov. 2014.

This project was funded by a USDA-TASC grant We are grateful to Nutek Corporation, Veg Fresh Farms, Dr. Jason Keller, and Bob McClain of the California Pear Advisory Board for their assistance. ${ }^{1}$ To whom reprint requests should be addressed; e-mail Prakash@chapman.edu.
(California Pear Advisory Board, Pear Pest Management Research Fund, California Specialty Crops Council, University of California Cooperative Extension, 2011).

Methyl bromide (MB) is a common fumigant for quarantine treatment in the United States (Drake et al., 2003; Environmental Protection Agency, 2014; Methyl Bromide Technical Options Committee, 2011). However, MB has been identified as a controlled ozone-depleting chemical by the Montreal Protocol since 1992. Although the use of postharvest fumigation is not scheduled for a phaseout, the use of $\mathrm{MB}$ will continue to decrease; thus, alternative phytosanitary measures to MB are needed.

Ionizing irradiation disrupts the deoxyribonucleic acid, which leads to the inability of the cell to replicate and cell death. Insects are highly vulnerable to irradiation and a dose of 0.05 to 0.15 kiloGray (kGy) is sufficient to sterilize most insects of concern (Miller, 2005). The USDA-APHIS has set an irradiation phytosanitary dose target of $0.15 \mathrm{kGy}$ for the tephritid fruit fly and $0.4 \mathrm{kGy}$ for other insects that do not include the pupa and adult stages of Lepidoptera [USDA-Animal and Plant Health Inspection Service-Plant Protection and Quarantine (USDA APHIS PPQ), 2013]. The U.S. Food and Drug Administration (FDA) allows a maximum of 1.0-kGy irradiation dose on fresh produce (FDA, 2011); thus, 0.40 to $1.0 \mathrm{kGy}$ is within the permissible dose range for fresh fruit.

Previous studies indicate that irradiation affects the enzymes involved in ripening of pears (Maxie et al., 1966; Wani et al., 2008). 'Anjou' and 'Bosc' pears ripened at a slower rate after irradiation exposure and allowed for one additional day of shelf life (Drake et al., 1999). Abolhassani et al. (2013) also reported that 'Bartlett' pears experienced a delay in ripening of 1 to $2 \mathrm{~d}$ when subjected to a minimum dose of $0.4 \mathrm{kGy}$.

Pears are susceptible to postharvest bruising and become more vulnerable after the mature-green stage when the fruit begin to soften during ripening (Abolhassani et al., 2013; Mitcham et al., 1996). An additional step in the supply chain such as irradiation and the associated handling could potentially elicit a wound response or increase the susceptibility to bruising. The target dose for phytosanitary treatment is $0.4 \mathrm{kGy}$; however, during commercial treatment, some portions of the fruit can be exposed to dose levels twice as high, depending on the size of the cartons, density of the fruit, packing density, and irradiation modality. Abolhassani et al. (2013) observed increased bruising in early-harvest pears irradiated at a minimum dose of $0.80 \mathrm{kGy}$. Signs of bruising are manifested as the fruit ripens and handling as would occur in a grocery situation can exacerbate bruising symptoms. The objective of this study was to determine the effect of phytosanitary irradiation on the ripening quality of California-grown 'Bartlett' pears under simulated commercial conditions of treatment and retail display where they would be exposed to handling typical in grocery stores. After exposure to irradiation treatment, the pears were evaluated daily during ripening for changes in respiration rate, ethylene production, and quality attributes followed by sensory testing at peak ripeness.

\section{Material and Methods}

Sample attainment. Size 135 'Bartlett' pears (Pyrus communis L.) were hand-harvested on 20 July 2012 from the San Joaquin Delta (River) for the early harvest and on 26 Aug. 2012 from Lake County (Mountain) for late-harvest pears. The River pears were picked when pears achieved a firmness of 80.1 to $89.0 \mathrm{~N}$ (18 to $20 \mathrm{lbs}$ force), and Mountain pears were picked at a firmness of $\approx 66.7 \mathrm{~N}(\approx 15 \mathrm{lbs}$ force $)$. Samples were placed in plastic bins and were transported to a commercial packing house in Exeter, CA, on the same day as harvest. At the packing house, the fruit were washed in a float tank with 100 to $150 \mathrm{ppm}$ chlorinated water maintained at a $\mathrm{pH}$ of 6 to 7 . The pears were transferred to a sorting platform and then handpacked into $16.3-\mathrm{kg}$ tight-fill cartons measuring $0.43 \mathrm{~m}$ (length) $\times 0.33 \mathrm{~m}$ (width) $\times 0.22 \mathrm{~m}$ (height). The cartons of pears were then forcedair cooled to 1 to $2{ }^{\circ} \mathrm{C}$ and stored for 1 to 3 weeks until shipment in a refrigerated truck to Nutek Corporation (Hayward, CA), a distance of $362 \mathrm{~km}$ for X-ray radiation treatment. 


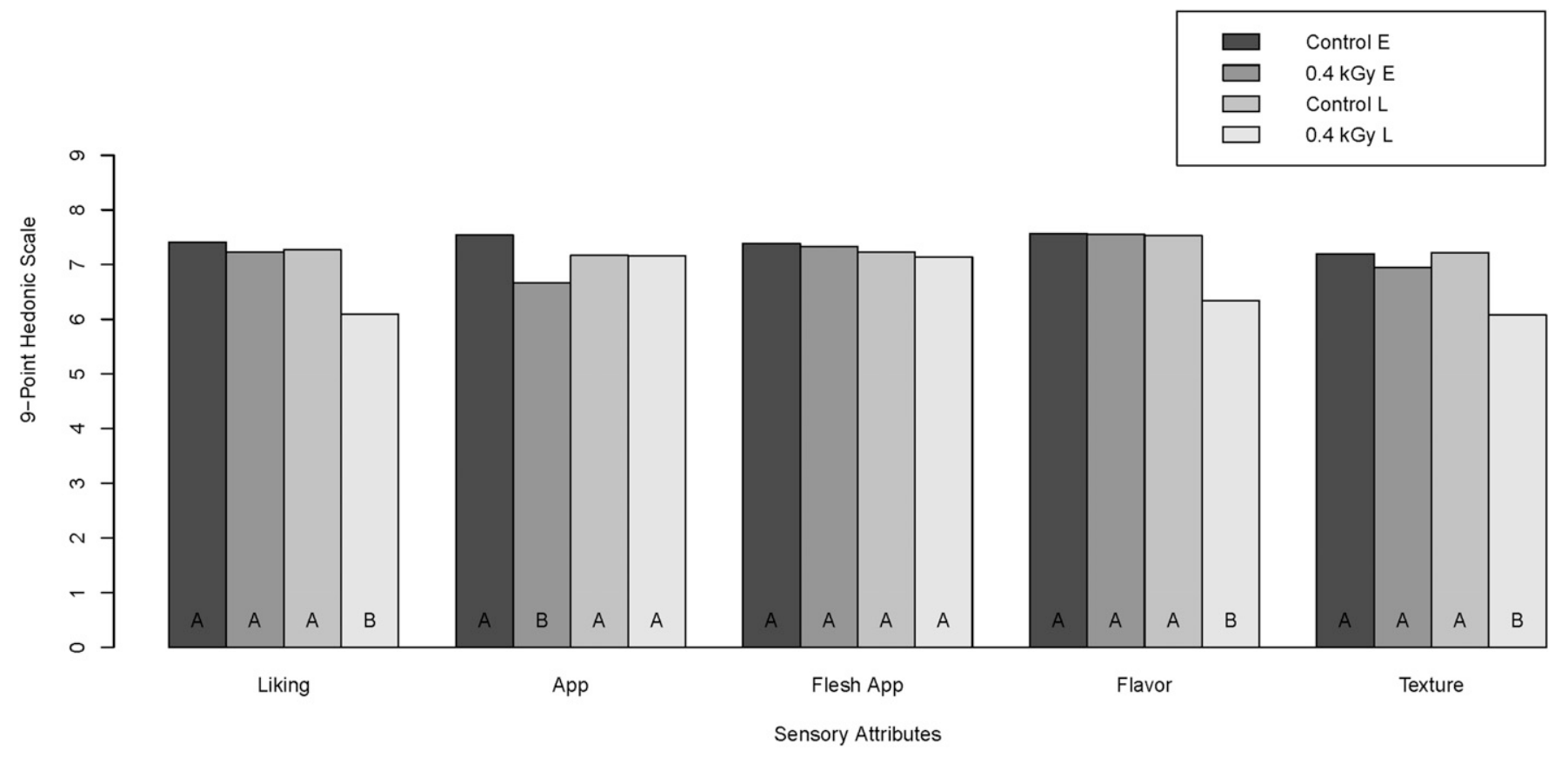

Fig. 1. Hedonic scores for overall liking, appearance (App), flesh appearance (Flesh App), flavor, and texture for control and irradiated early (E) (n=101) and late (L) $(n=89)$ harvest pears measured at peak ripeness. Values designated with the same letters within the same harvest season and for each attribute are not significantly different, $P<0.05$.

$X$-ray radiation. Pears were treated during the mature green stage at a target dose of $0.4 \mathrm{kGy}$ at Nutek Corporation, which was equipped with a $10-\mathrm{MeV}$ electron beam accelerator. The X-ray converter was made of copper cooled with water, and the conversion rate from the electron beam to X-ray was $7 \%$ to $10 \%$ (Mevex Corp., Ottawa, Ontario, Canada). Ten cartons of pears were placed in a single layer with the wider dimension facing the electron beams. The speed of the conveyor was $0.20 \mathrm{~m} \cdot \mathrm{s}^{-1}$ to the source of the beam and $0.005 \mathrm{~m} \cdot \mathrm{s}^{-1}$ at the source. After the first pass, the containers were rotated $180^{\circ}$ and treated again to receive a double-sided treatment. Dose distribution was determined by distributing 30 to 35 alanine (Kodak, Rochester, New York) and radiochromic film dosimeters (GEX Corporation, Centennial, CO) in identical dummy cartons to achieve a three-dimensional dose map and to determine the reference dose. During treatment, a reference dosimeter was placed externally to verify the treatment dose. A range of 0.40 to $0.79 \mathrm{kGy}$ was achieved within the pear cases for a dose uniformity ratio of 2.0. Ten cartons of pears were not irradiated and labeled as controls. After irradiation, the pears were transported $644 \mathrm{~km}$ to Chapman University (Orange, $\mathrm{CA}$ ) in a refrigerated truck maintained at 1 to $3{ }^{\circ} \mathrm{C}$.

Cold storage and ripening. Pears were stored in their cartons at 3 to $5{ }^{\circ} \mathrm{C}$ and $93 \%$ relative humidity (RH) for 1 to 2 weeks after radiation treatment. Retail display was based on observation of actual treatment of pears in local supermarkets. Although the conditions vary somewhat per store, the most commonly used conditions were used in this study. To mimic retail conditions, all the pears contained in four cartons were unpacked and stacked three pears high and allowed to ripen at $20{ }^{\circ} \mathrm{C}$ and $80 \%$ RH. Early-harvest pears ripened for $8 \mathrm{~d}$ and late harvest for $6 \mathrm{~d}$. On each day during ripening, a series of physicochemical tests were conducted as detailed below. Once the pears were ripe, affective sensory testing was conducted using a consumer panel.

\section{Sensory evaluation}

Affective testing. Sensory testing followed ASTM Committee E-18 guidelines (Chambers and Wolf, 1996; Lawless and Heymann, 2010; Stone and Sidel, 2004). Once the pears reached peak ripeness (firmness reading of 3 to 5 force in pounds or 13.3 to $22.2 \mathrm{~N}$ ), affective testing was conducted with 80 to 100 consumers to determine the degree of liking of appearance (peel and internal flesh), flavor, and texture using a 9-point hedonic scale (Peryam and Pilgrim, 1957). A just-about-right (JAR) test was also used to determine the sweetness and firmness on a 5-point scale (Rothman and Parker, 2009).

Consumer panelists were given four slices each of control and treated pears on paper boats that were coded with three-digit randomized numbers. The sample order was also randomized to reduce order bias. Between samples, consumers were allowed to cleanse their palates with unsalted soda crackers and drinking water (Chambers and Wolf, 1996). Sensory testing was administered in individual booths and data were collected using SIMS 2000 Sensory Evaluation software (Sensory Computer Systems, Berkeley Heights, NJ).

\section{Analytical tests}

Carbon dioxide and ethylene analyses. Standards for carbon dioxide $\left(\mathrm{CO}_{2}\right)$ and ethylene $\left(\mathrm{C}_{2} \mathrm{H}_{4}\right)$ were prepared in airtight $15.2 \mathrm{~cm} \times 15.2-\mathrm{cm}$ gas sampling bags (Fisher
Scientific, Hampton, NH) equipped with an Alltech general-purpose septa (Fisher Scientific). Air was removed from the gas bags by vacuum. Each bag was then filled with inert nitrogen gas (Air Liquide America Specialty Gases, LLC, Plumsteadville, PA) and vacuumed again. Starting with a custom gas mixture of 20,000 ppm $\mathrm{CO}_{2}$ and $101 \mathrm{ppm}$ $\mathrm{C}_{2} \mathrm{H}_{4}$ (Air Liquide America Specialty Gases, LLC), dilutions ranging from 101 to 20,000 ppm for $\mathrm{CO}_{2}$ and 0.02 to $101 \mathrm{ppm}$ for $\mathrm{C}_{2} \mathrm{H}_{4}$ were prepared for a standard curve using nitrogen gas as the diluent. A $10-\mathrm{mL}$ BD Luer-Lok Tip syringe (Cole Parmer, Vernon Hills, IL) equipped with a one-way male slip stopcock (Cole Parmer) and a needle attachment (Cole Parmer) was used to extract the gases from the gas bags. The extracted gasses were injected into a SRI $8610 \mathrm{C}$ gas chromatograph (GC) (SRI Instruments, Torrance, $\mathrm{CA}$ ) with a $2.0-\mathrm{mL}$ or $0.1-\mathrm{mL}$ sample loop. The GC was equipped with a flame ionizing detector (FID) to detect $\mathrm{C}_{2} \mathrm{H}_{4}$ coupled with an inline methanizer to convert $\mathrm{CO}_{2}$ into $\mathrm{CH}_{4}$ for subsequent detection through the FID. Nitrogen gas was used as the carrier at a flow rate of $30 \mathrm{~mL} \cdot \mathrm{min}^{-1}$. Gas samples were run on a HayeSep D column, the detector temperature was $300{ }^{\circ} \mathrm{C}$, and the column temperature was $80{ }^{\circ} \mathrm{C}$.

Carbon dioxide and ethylene production were measured daily during ripening using a static system as described by Saltveit (2012). Twelve pears from each treatment (control and irradiated) were weighed and placed in individual 4-L glass jars (California Glass Company, Oakland, CA), six pears per jar, two jars per treatment. The jars were sealed with size 15 rubber stoppers (Plasticoid Company, Elkton, MD) equipped with two holes through which two $0.00635-\mathrm{m}$ internal 


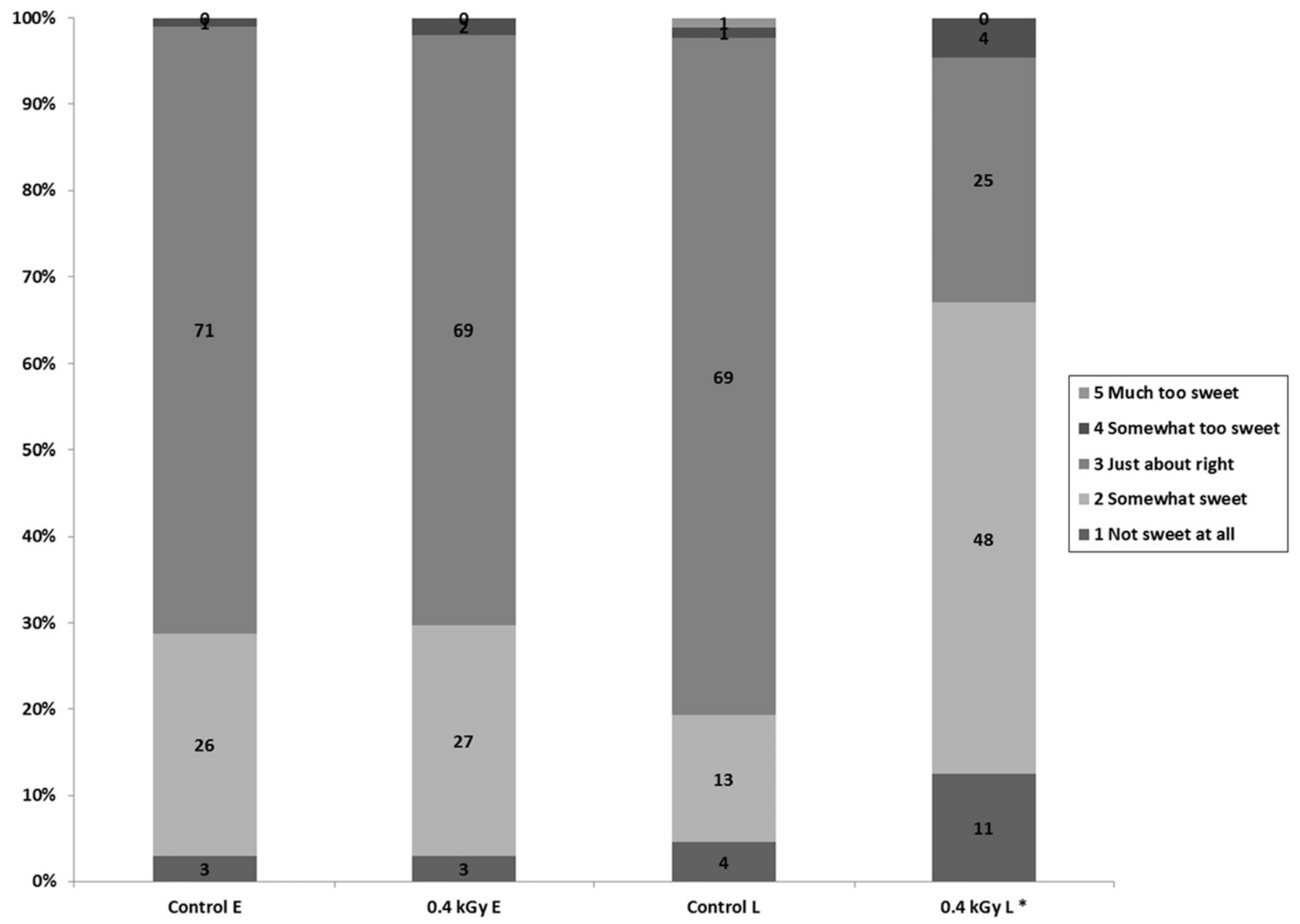

Fig. 2. Frequency analysis of just-about-right (JAR) scores for sweetness (A) and firmness $(\mathbf{B})$ for control and irradiated early (E) (n $=101)$ and late $(\mathrm{L})(\mathrm{n}=89)$ harvest pears measured at peak ripeness. *Significant difference between the control and irradiated late-harvest pears for sweetness, $P<0.05$.

diameter Polyflo plastic tubes (California Equipment, Sacramento, CA) were placed. A $0.00476-\mathrm{m}$ internal diameter $\times 0.00159-\mathrm{m}$ wall thickness latex tubing (Primeline Industries, Akron, $\mathrm{OH}$ ) connected the two plastic tubes allowing secure gas extraction using a syringe. Each jar was allowed to equilibrate for $1 \mathrm{~h}$, and $10 \mathrm{~mL}$ of gas was extracted at intervals of 60,65 , and $70 \mathrm{~min}$ and analyzed in the GC in triplicate. The respiration rate and ethylene production rate were calculated with the following equations (Saltveit, 2012).

$$
\begin{aligned}
\frac{\frac{\mathrm{mLCO}}{\mathrm{kg}}}{\mathrm{h}}= & {\left[\mathrm{CO}_{2}\right] \frac{\mathrm{mL}}{\mathrm{L}} \times \frac{\text { Void Space }(\mathrm{L})}{\text { Fruit Weight }(\mathrm{kg})} } \\
& \times \frac{1}{\mathrm{t}(\mathrm{h})}
\end{aligned}
$$

$$
\begin{aligned}
\frac{\frac{\mu \mathrm{L} \mathrm{C}_{2} \mathrm{H}_{4}}{\mathrm{~kg}}}{\mathrm{~h}}= & {\left[\mathrm{C}_{2} \mathrm{H}_{4}\right] \frac{\mu \mathrm{L}}{\mathrm{L}} \times \frac{\text { Void Space }(\mathrm{L})}{\text { Fruit Weight }(\mathrm{kg})} } \\
& \times \frac{1}{\mathrm{t}(\mathrm{h})}
\end{aligned}
$$

Color. Pear color was measured with a CM-2500d colorimeter/spectrophotometer (Konica Minolta Optics, Inc., Chiyoda, Tokyo,
Japan) at the equatorial section between the stem end and calyx of the fruit on two opposite points of each of 20 randomly selected pears from each treatment. The $\mathrm{L}^{*}, \mathrm{a}^{*}, \mathrm{~b}^{*}$, hue (identified with a color name), and saturation (or chroma, characteristic of the clarity/purity, and the intensity of the hues) values were recorded (Abolhassani et al., 2013; DelgadoVargas, 2003; Drake et al., 1999).

Firmness. The same 20 pears from color measurement were prepared for firmness testing by peeling opposite sides (dark and light sections) on the equatorial section between the stem end and calyx of the fruit. Firmness was measured using two instruments: a fruit pressure tester (penetrometer) Model FT327 (QA Supplies, Norfolk, VA) equipped with a 8 -mm tip and a TA.XT Plus Texture Analyzer (Stable Micro Systems, Godalming, Surrey, U.K.) equipped with a Magnus Taylor 8-mm probe. The texture analyzer probe speed was $4.0 \mathrm{~mm} \cdot \mathrm{s}^{-1}$ and penetrated $8 \mathrm{~mm}$ into each sample with the post-test speed at $10.0 \mathrm{~m} \cdot \mathrm{s}^{-1}$ after penetration of the fruit (Abolhassani et al., 2013). The peak force in Newtons was recorded.

Weight loss. The weight loss of two whole cartons from each treatment of pears was monitored daily during ripening using a SB32000 scale (Mettler Toledo, Columbus, OH).

Juice sample preparation. Immediately after the physical analysis, the same 20 pears from each treatment were juiced using an Elite Gourmet Maxi-matic Juice Extractor TS-738 (City of Industry, CA). The juice was filtered using six layers of cheesecloth to separate the fiber from the juice.

Titratable acidity. Five milliliters of filtered juice was combined with $50 \mathrm{~mL}$ of carbon dioxide-free deionized water and titrated with $0.1 \mathrm{~N} \mathrm{NaOH}$ until the $\mathrm{pH}$ reached an endpoint of 8.2 monitored with a pH $200 \mathrm{~m}$ (Hannah Instruments, Woonsocket, RI). Titratable acidity (TA) was measured in triplicate and percent malic acid was calculated using the equation (Nielsen, 2010):

\section{\%Malic Acid}

$=\mathrm{mL}$ base titrant $\times$ molarity of $\mathrm{NaOH}$ $\times 67.04$

mL sample $\times 10$

Total soluble solids. Total soluble solids (TSS) of the pears was measured using a 


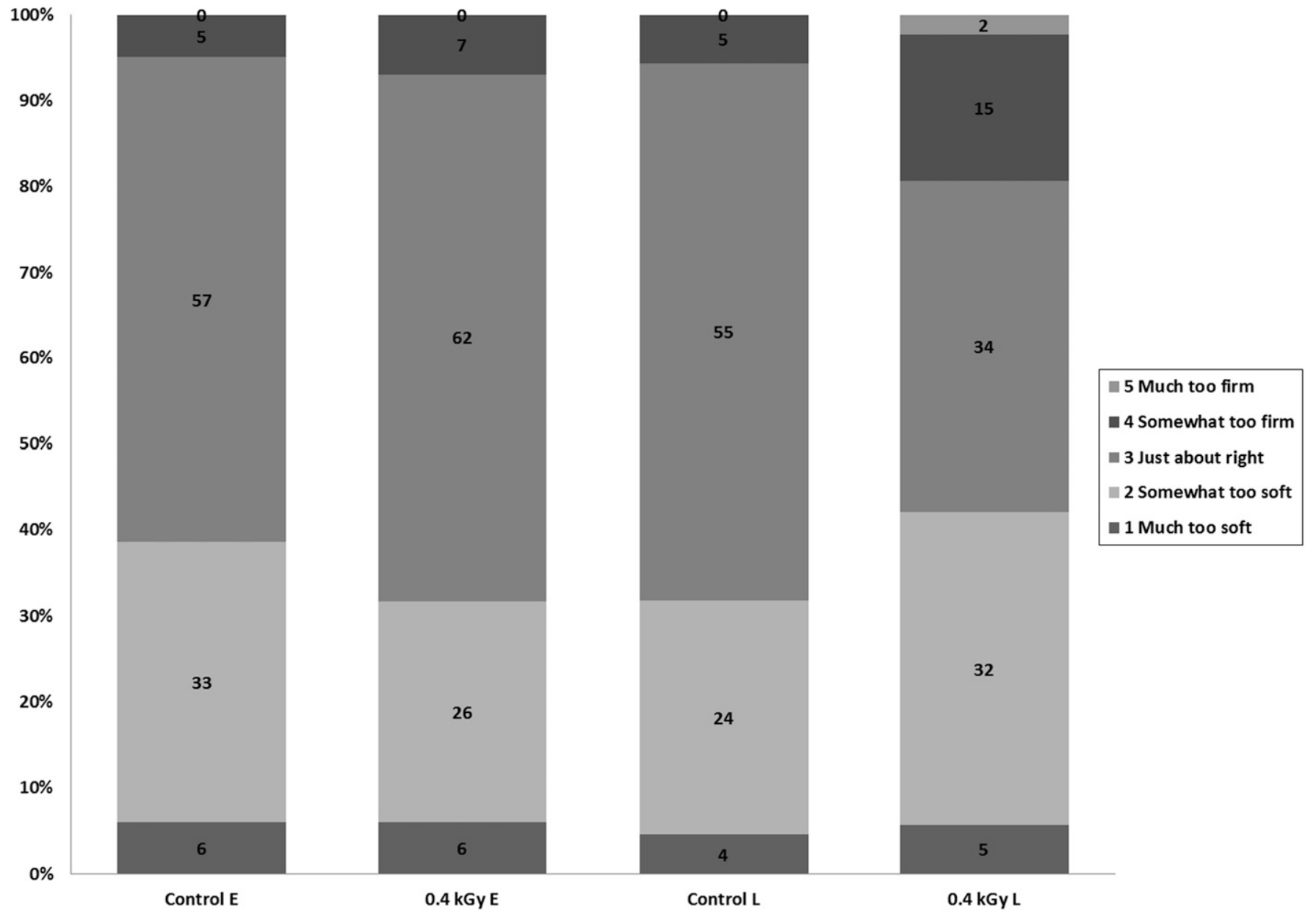

Fig. 2. (Continued)

digital PAL-1 Pocket Refractometer (ATAGO Co., Minato-ku, Tokyo, Japan). Approximately $0.3 \mathrm{~mL}$ of the extracted pear juice was placed on the sampling prism of the refractometer. These measurements were conducted in triplicate.

\section{Statistical analysis}

A longitudinal randomized treatment design with repeated measurements was used. The R statistical software package (R Development Core Team, 2011) for linear mixed effect models (lme4) was applied to all analytical data. Statistical models with random effects for sensory analysis were included in the model for the repeated measurements corresponding to individual panelists (Abolhassani et al., 2013). Both treatment and time (days) were categorical, and cluster or longitudinal correlations was applied. The most appropriate model was chosen based on significant predictors and the existence of complex interactions between treatment and ripening time (McDonald et al., 2012). Early- and lateharvest pears were analyzed separately because of the apparent differences in ripening rates.

\section{Results and Discussion}

\section{Sensory evaluation}

Affective testing. Consumers scored all the attributes for the control pears for both early and late harvest at $\approx 7.0$, which equates to "like moderately" (Fig. 1). For the earlyharvest pears, the only attribute that was negatively affected by radiation was the external appearance. Abolhassani et al. (2013) made a similar observation for pears irradiated at $0.80 \mathrm{kGy}$. Internal flesh appearance was unaffected in both the early- and late-harvest pears and is consistent with the findings of Drake et al. (1999) where internal color of irradiated 'Anjou' and 'Bosc' pears was not different from that of the control. Overall liking for late-harvest pears showed that irradiated pears were liked less (score of 6.1) than the control $(P<0.05)$. Flavor (6.34) and texture (6.08) were the attributes most affected by radiation, but appearance was liked the same for both control and irradiated pears. Despite the decrease in the score for texture liking, the firmness JAR score was not significantly different, suggesting that the change in texture was perceived by consumers as different from firmness (Fig. 2). Sweetness was also found to be less than preferred for the irradiated sample, and the JAR score showed that more consumers scored these pears at "somewhat sweet" (Fig. 2). In contrast, Wani et al. (2008) found that pears irradiated at 1.5 to $1.7 \mathrm{kGy}$ had higher sensory scores for overall color, texture, and taste, which they attributed to the rapid rate of ripening and senescence in the non-irradiated control samples.

\section{Analytical tests}

Carbon dioxide and ethylene production. Peak $\mathrm{CO}_{2}$ and $\mathrm{C}_{2} \mathrm{H}_{4}$ production rates were observed on Day 5 (Fig. 3) for early-harvest pears. Irradiated pears produced significantly less $\mathrm{C}_{2} \mathrm{H}_{4}$ than the control $(P<0.05)$ between Days 3 and 8.

The respiration peak was reached on Day 2 for the late-harvest pears (Fig. 4). The rapid climacteric peak suggests that the late-harvest pears might have started to ripen during storage. For this set of pears, irradiation resulted in significantly more $\mathrm{CO}_{2}$ and significantly less $\mathrm{C}_{2} \mathrm{H}_{4}$ than the control $(P<0.05)$ throughout the ripening period except for ethylene on Day 1, which was significantly higher in the irradiated pears. 


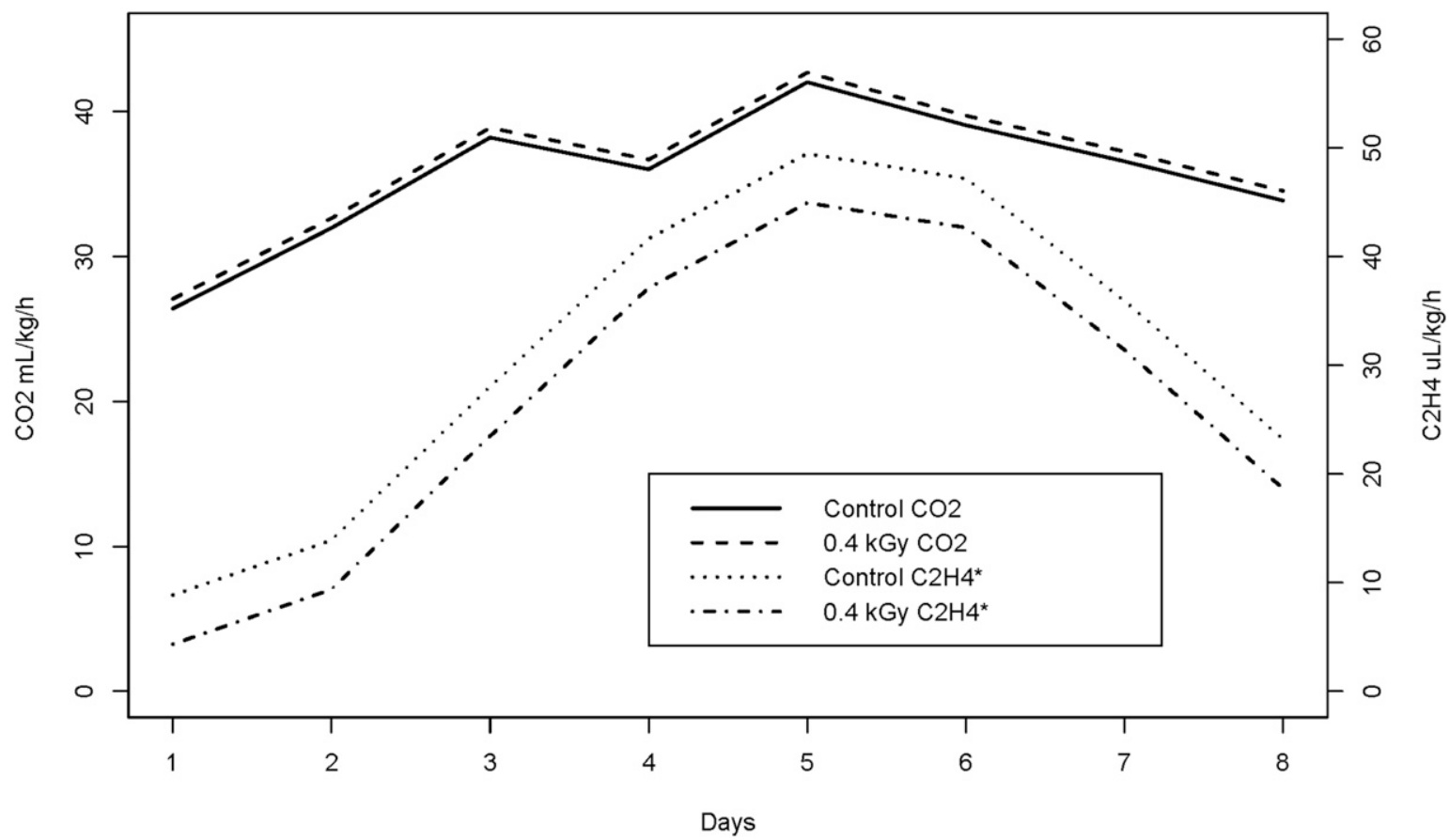

Fig. 3. $\mathrm{CO}_{2}\left(\mathrm{~mL} \cdot \mathrm{kg}^{-1} \cdot \mathrm{h}^{-1}\right)$ and $\mathrm{C}_{2} \mathrm{H}_{4}$ production $\left(\mu \mathrm{L} \cdot \mathrm{kg}^{-1} \cdot \mathrm{h}^{-1}\right)$ of early harvest control and irradiated pears evaluated daily during ripening. * Significant difference between the control and irradiated pears in $\mathrm{C}_{2} \mathrm{H}_{4}$ production, $P<0.05$.

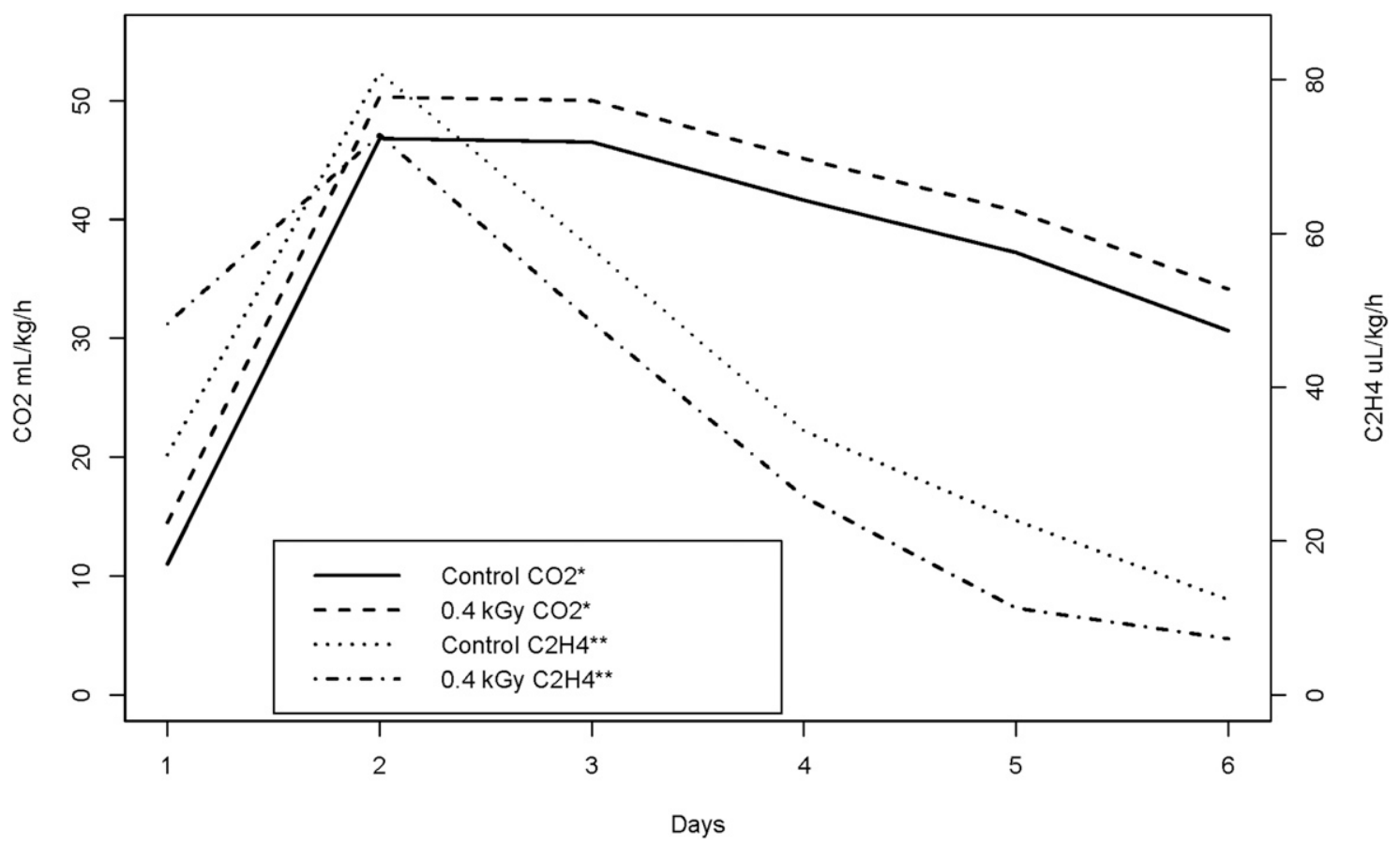

Fig. 4. $\mathrm{CO}_{2}$ production $\left(\mathrm{mL} \cdot \mathrm{kg}^{-1} \cdot \mathrm{h}^{-1}\right)$ and $\mathrm{C}_{2} \mathrm{H}_{4}$ production $\left(\mu \mathrm{L} \cdot \mathrm{kg}^{-1} \cdot \mathrm{h}^{-1}\right)$ of late harvest control and irradiated pears evaluated daily during ripening. * Significant difference between the control and irradiated pears for $\mathrm{CO}_{2}$ production. **Significant difference between the control and irradiated pears for $\mathrm{C}_{2} \mathrm{H}_{4}$ production, $P<0.05$.

Similar results were reported by Maxie et al. (1966), who observed that in pears irradiated at $3.0 \mathrm{kGy}, \mathrm{C}_{2} \mathrm{H}_{4}$ production was initially increased at the pre-climateric phase after irradiation treatment and then declined to less than the control during the rest of the ripening period. It appears that pears respond to radiation with increased ethylene production, but the increase is transient. The initial ethylene increase and higher $\mathrm{CO}_{2}$ levels of the irradiated pears suggest that the late-harvest pears responded to irradiation treatment even at a minimum dose of $0.4 \mathrm{kGy}$ similar to a wound response (Agar and Mitcham, 2000; Gunes et al., 2000). Irradiation and other stresses can induce the initial increase of $\mathrm{C}_{2} \mathrm{H}_{4}$ production by transcriptional activation and synthesis of 1-aminocyclopropane1-carboxylate synthase. Conversely, decreased $\mathrm{C}_{2} \mathrm{H}_{4}$ production has been attributed to the inhibition of protein synthesis by irradiation (Chervin, 1992). A similar response has been observed in 'Bartlett' pears irradiated at $1 \mathrm{kGy}$ or greater (Maxie et al., 1966; Wani et al., 2008) and apple slices at $1.2 \mathrm{kGy}$ or greater (Gunes et al., 2000). Lowered ethylene could cause altered ripening, which could affect the hydrolysis of starch to sugar resulting in increased mealy textures and lower sweetness. These attributes may have resulted in the consumers scoring the irradiated late-harvest pears as "like slightly" as compared with "like moderately" for the control. 


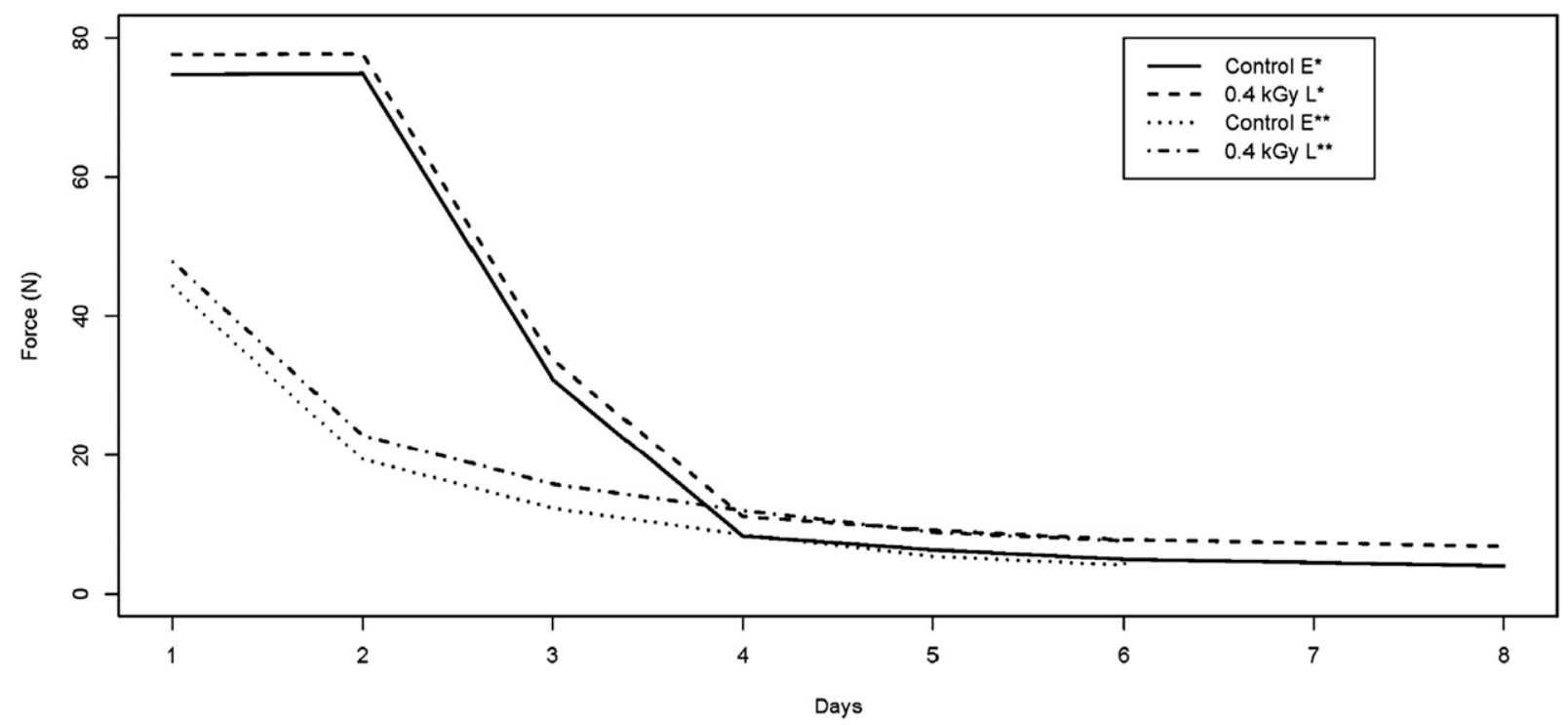

Fig. 5. Effect of irradiation during ripening on estimated means of the peak force using an 8-mm penetration probe on early (E) and late (L) harvest pears. *Significant difference between the control and irradiated early-harvest pears. ${ }^{* *}$ Significant difference between the control and irradiated late-harvest pears, $P<0.05$.

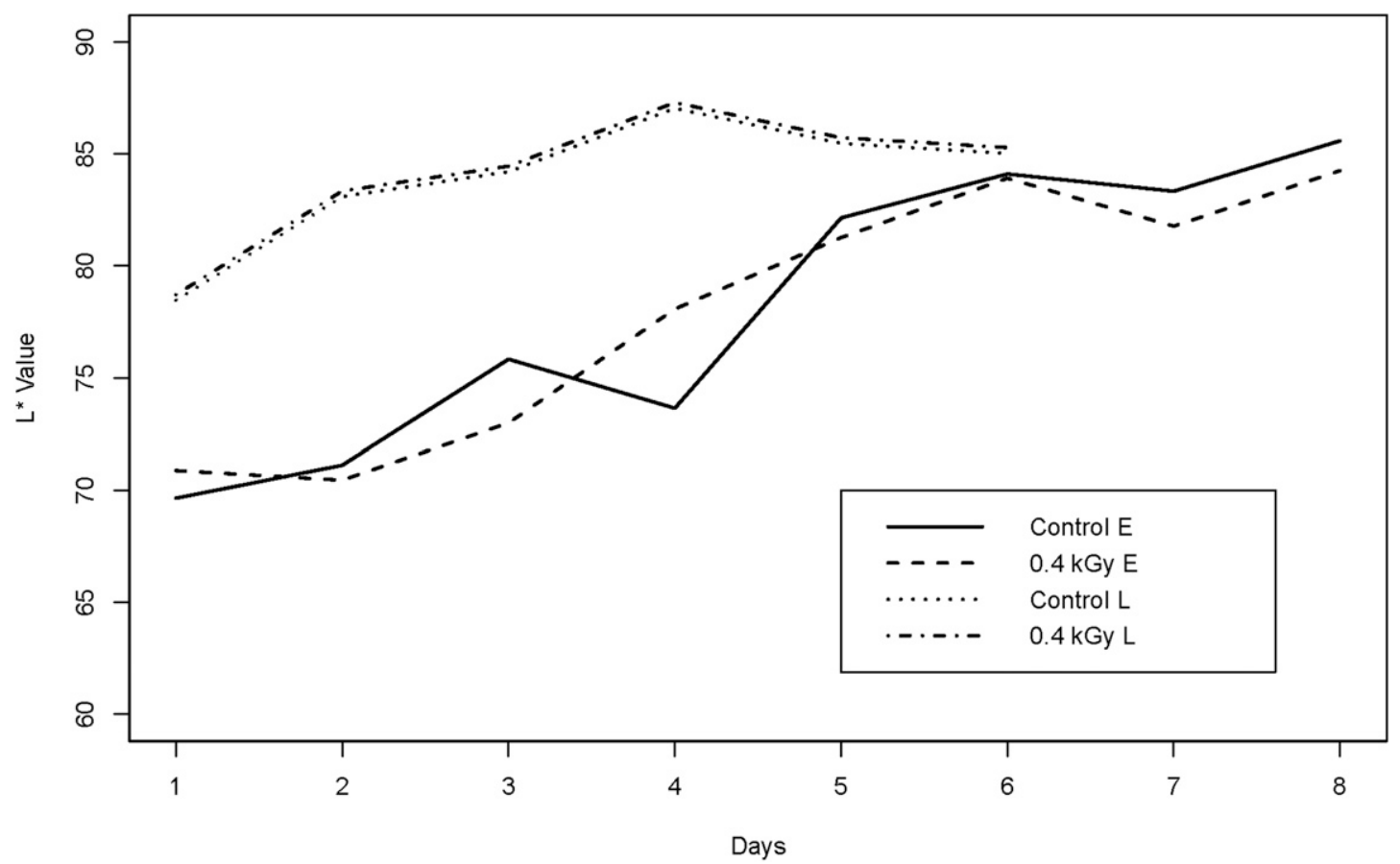

Fig. 6. Hunter L* (lightness) estimated mean values for early (E) and late (L) harvest pears, control and irradiated pears, measured daily during ripening.

Firmness. The measurements obtained using the texture analyzer and the penetrometer were similar; thus, only data for the texture analyzer are shown (Fig. 5). The early-harvest pears were firmer than the late-harvest pears, which could be because ripening had already been started in the late-harvest pears but in general, the irradiated pears were significantly more firm than the control $(P<0.05)$. The conversion of insoluble pectic fractions to the soluble forms by protopectinase and pectin methyl esterase enzymes occurs during ripening and causes a decrease in firmness. Irradiation is known to inhibit activity of these enzymes in pears, thus retaining firmness (Hussain et al., 2010; Maxie et al., 1966; Wani et al., 2008).

Color. Both early- and late-harvest pears did not exhibit a significant difference in $\mathrm{L}^{*}$ values as a result of irradiation, but $\mathrm{L}^{*}$ values increased during ripening as the color changed from green to yellow (Fig. 6). The lower $\mathrm{L}^{*}$ and $\mathrm{a}^{*}$ values of the early-harvest pears reflect the fact that they were greener than the late-harvest pears, which had started to ripen during storage.

There were no differences $(P>0.05)$ for $\mathrm{a}^{*}$ values between the control and irradiated pears and $a^{*}$ values increased significantly over time indicating a decrease in "greenness" (Fig. 7). The higher a* values of the late-harvest pears as compared with the early-harvest pears are consistent with our gas and texture data that show that the late-harvest pears were at a later ripening stage. Loss of green color of pears during ripening is the result of the conversion of chloroplasts (green pigment) into chromoplasts (yellow and red carotenoid pigments) through enzyme-mediated processes involving chlorophyllase, chlorophyll oxidase, and peroxidase (Stanley, 1991). Irradiation is thought to have an inhibitory effect on the chlorophyllase enzyme, and free radicals produced from ionizing irradiation could 


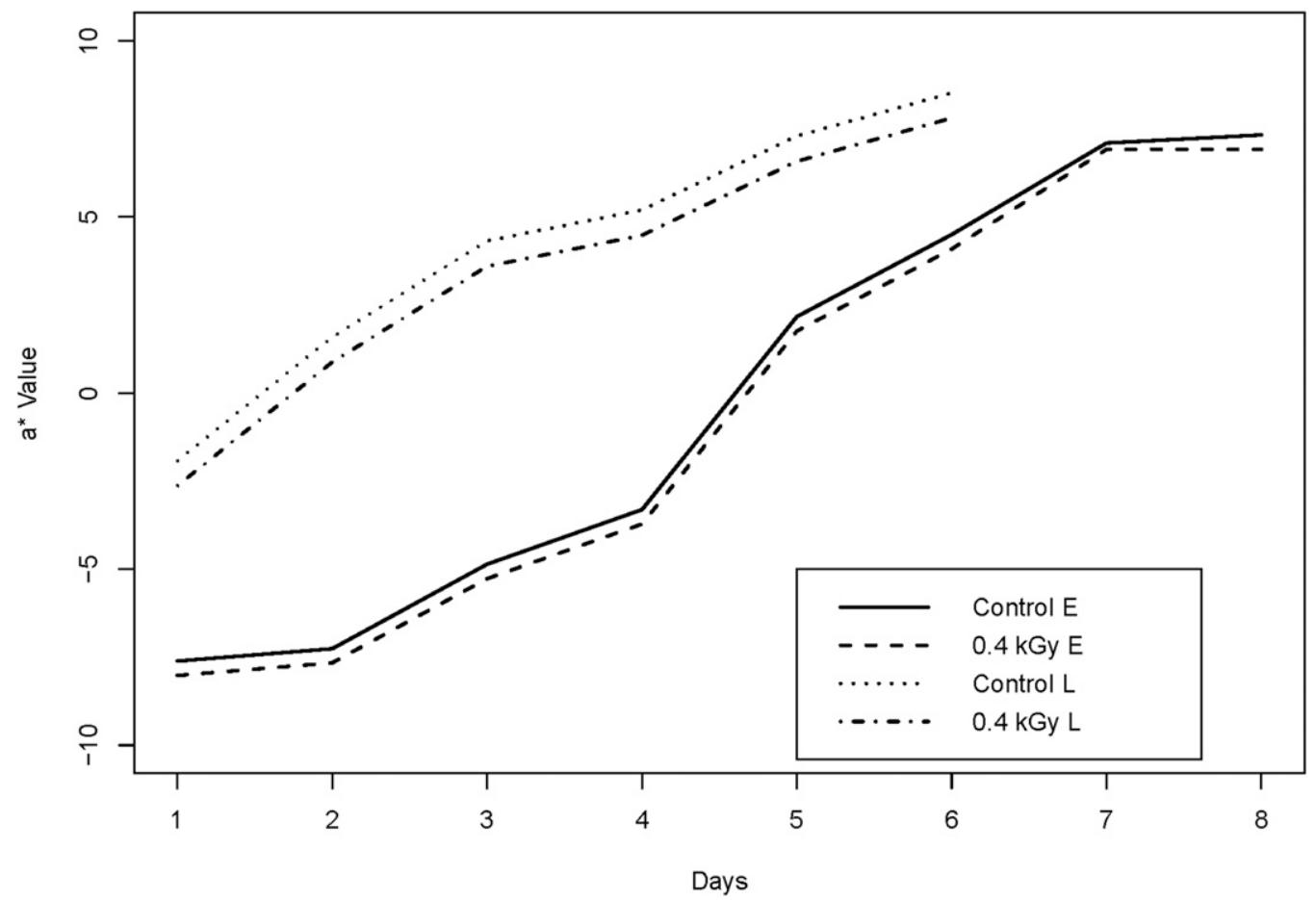

Fig. 7. Hunter $\mathrm{a}^{*}$ (green - red) estimated mean values for early (E) and late (L) harvest pears, control and irradiated pears, measured daily during ripening.

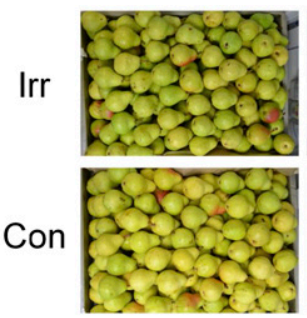

1

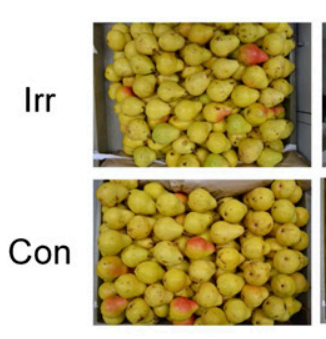

4

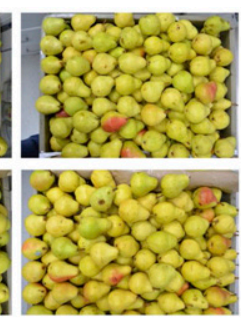

2

Day

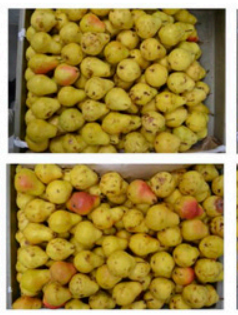

5

Day

A

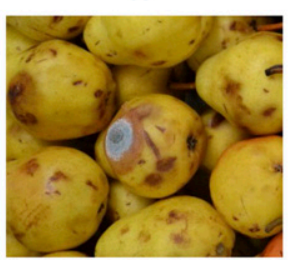

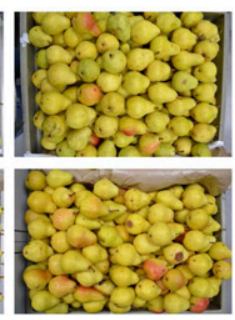

3

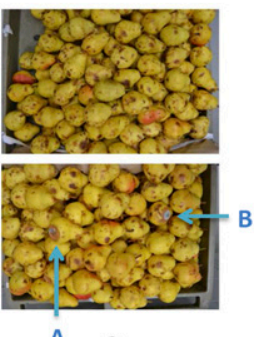

A 6

B

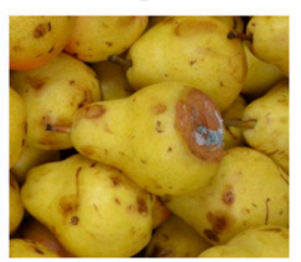

Fig. 8. Ripening of late harvest control (Con) and irradiated (Irr) pears subject to simulated retail market handling and display. Arrows indicate sites of visual mold growth on bruised pears.

act as stress signals to slow the degradation of chlorophyll (Fan and Thayer, 2001; Hussain et al., 2010). Wani et al. (2008) found that the chlorophyll content of 'Bartlett' pears was significantly lower in control samples than pears irradiated up to $2.0 \mathrm{kGy}$.
There were no significant differences in $\mathrm{b}^{*}$ values, chroma, or hue between pears irradiated at a minimum dose of $0.4 \mathrm{kGy}$ and the control (data not shown), although these values changed during the ripening process as pears turned yellow.

Retail display simulation. Each day during ripening, the stacks were rearranged to place unripe fruit at the bottom and ripe fruit on top as commonly done in grocery stores. In the first few days of ripening, the irradiated pears appeared to be greener than the control pears. At the onset of senescence, the control pears showed more signs of mold growth and bruising than the irradiated pears. Notable visual damage included scuffing and impact bruising. Browning at the calyx and stem end was also noted in both the irradiated and control samples. The greater softness of the control pears made them more susceptible to bruising resulting from handling, and mold was observed growing in the heavily bruised sections of the fruit (Fig. 8 ). Thus, the higher firmness of the irradiated pears helped maintain pear quality in the retail market simulation.

Weight loss. There was no difference in weight loss between the irradiated and control early-harvest pears (data not shown). Late-harvest irradiated pears lost significantly more weight than the control $(P<$ $0.05)$; however, the difference the result of treatment was only $\approx 0.5 \%$. In contrast, Wani et al. (2008) observed that 'Bartlett' pears irradiated at 0.8 to $2.0 \mathrm{kGy}$ showed significantly lower weight loss compared with the non-irradiated control after $7 \mathrm{~d}$ of ambient storage (Wani et al., 2008). Lower weight loss has been attributed to the effect of irradiation on the delay of ripening and senescence, which could reduce the weight 
Table 1. Changes in titratable acidity (TA; \% malic acid) and total soluble solids (TSS) of early (E) and late (L) harvest control and irradiated 'Bartlett' pears during ripening.

\begin{tabular}{|c|c|c|c|c|c|c|c|c|}
\hline \multicolumn{9}{|c|}{ Ripening period (d) } \\
\hline & 1 & 2 & 3 & 4 & 5 & 6 & 7 & 8 \\
\hline \multicolumn{9}{|c|}{ TA (\% malic acid $)$} \\
\hline Control $\mathrm{E}^{\mathrm{S}}$ & 0.275 & 0.245 & 0.303 & 0.240 & 0.278 & 0.288 & 0.280 & 0.311 \\
\hline $0.4 \mathrm{kGy} \mathrm{E}^{\mathrm{s}}$ & 0.255 & 0.225 & 0.284 & 0.220 & 0.259 & 0.269 & 0.260 & 0.292 \\
\hline Control $\mathrm{L}^{\mathrm{S}}$ & 0.251 & 0.244 & 0.248 & 0.254 & 0.258 & 0.246 & 一 & - \\
\hline $0.4 \mathrm{kGy} \mathrm{L}{ }^{\mathrm{s}}$ & 0.203 & 0.196 & 0.199 & 0.206 & 0.209 & 0.198 & - & 一 \\
\hline \multicolumn{9}{|l|}{ TSS } \\
\hline Control E NS & 12.67 & 13.50 & 12.80 & 13.30 & 13.23 & 12.70 & 13.30 & 12.73 \\
\hline 0.4 kGy E NS & 12.90 & 12.97 & 13.07 & 12.93 & 13.73 & 12.90 & 13.23 & 12.70 \\
\hline Control $\mathrm{L}^{\mathrm{S}}$ & 13.70 & 12.53 & 13.03 & 12.90 & 12.80 & 14.30 & - & - \\
\hline $0.4 \mathrm{kGy} \mathrm{L}^{\mathrm{s}}$ & 12.07 & 12.23 & 13.80 & 10.77 & 12.90 & 12.63 & - & - \\
\hline
\end{tabular}

$\mathrm{s}_{=}$significant differences between the control and irradiated pears during ripening, $P<0.05$. NS $=$ nonsignificant differences between control and irradiated pears.

loss of irradiated fruit in comparison with non-irradiated fruit (Dong et al., 1994; Lester and Whitaker, 1996; Massey, 1964).

Total soluble solids. Early harvest pears did not show a significant difference in TSS between irradiated and the control where TSS content fluctuated between 12.5 and $13.0{ }^{\circ}$ Brix during ripening (Table 1). On most days, late-harvest irradiated pears exhibited significantly less TSS than the control. Similar results with reduced TSS in irradiated pears attributed to delayed ripening have been reported (Abolhassani et al., 2013).

Fruit ripening results in the degradation of polysaccharides into simple sugars, which increases TSS (Cruz et al., 2012; Hussain et al., 2008). Generally, at low dose levels, there is little effect on sugars. Gamma irradiation at $1.0 \mathrm{kGy}$ or less did not show any significant changes to carbohydrate concentration in 'Anjou' and 'Bosc' pears or 'Fuji' and 'Granny Smith' apples. In our study, however, TSS was significantly lower for late-harvest irradiated pears as compared with the control. This could be attributed to the respiration rate, which was significantly higher in the irradiated pears. This result plus comments from consumers reporting a mealy texture suggests a disorder in starch metabolism. A similar phenomenon is seen in pears that become mealy without adequate ethylene development (Agar et al., 1999).

Titratable acidity. Pears irradiated at a minimum dose of $0.4 \mathrm{kGy}$ exhibited significantly less malic acid content than the controls during ripening (Table 1). However, the maximum difference between irradiated and control pears was $0.05 \%$ for both harvests. Similarly, a decrease in TA was observed in 'Le Conte' pears irradiated at $1.0 \mathrm{kGy}$ after $45 \mathrm{~d}$ of cold storage and retail display for 5 to $10 \mathrm{~d}$ under ambient temperatures (Hamid et al., 2012). The lower acid and sugar levels for irradiated pears could be the result of the higher respiration rate that uses sugar and acids as a substrate. In contrast, Wani et al. (2008) found that irradiated 'Bartlett' pears had higher acidity levels in both refrigerated and ambient conditions when compared with the control. They attributed the higher acid content of the irradiated pears to the delay of ripening.

\section{Conclusion}

The climacteric peak was not delayed as a result of irradiation, but the treatment resulted in lower ethylene and higher $\mathrm{CO}_{2}$ production as well as higher firmness values, which made pears less susceptible to bruising and mold development during the retail display simulation suggesting that irradiated pears can better withstand the handling associated with commercial distribution. The differences in the response of the two sets of pears to radiation may be attributed to the differences in harvest (early vs. late) but more likely the result of differences in the growing region (River vs. Mountain). This study shows that 'Bartlett' pears exposed to X-ray irradiation maintained shelf life and quality during ripening in a retail market simulation. This work also underscores the importance of testing fruit quality under conditions that would be encountered in commercial distribution. This research provided a baseline study of the effects of radiation on pears compared with an untreated control. Further work comparing irradiated fruit with fruit treated using other phytosanitary methods such as cold treatment is warranted.

\section{Literature Cited}

Abolhassani, Y., F. Caporaso, C. Rakovski, and A. Prakash. 2013. The effect of gamma irradiation as a phytosanitary treatment on physicochemical and sensory properties of Bartlett pears. J. Food Sci. 78:S1437-S1444.

Agar, I.T., W.V. Biasi, and E.J. Mitcham. 1999. Exogenous ethylene accelerates ripening responses in Bartlett pears regardless of maturity or growing region. Postharvest Biol. Technol. 17:67-78.

Agar, I.T. and E.J. Mitcham. 2000. Commercial handling influences quality and ripening of Bartlett pears. Calif. Agr. 54:34-37.

California Foundation for Agriculture in the Classroom. 2011. Pears commodity fact sheet. California foundation for agriculture in the classroom. Sacramento. 30 July 2012. <http:// www.cfaitc.org/factsheets/pdf/Pears.pdf $>$.

California Pear Advisory Board, Pear Pest Management Research Fund, California Speciality Crops Council, University of California Cooperative Extension. 2011. A pest management strategic plan for pear production in California. California Pear Advisory Board, Pear Pest Management Research Fund, California Specialty Crops Council, University of California Cooperative Extension. 18 Apr.
2012. <http://www.ipmcenters.org/pmsp/pdf/ CAPear.pdf $>$.

Chambers, E.C. and M.B. Wolf. 1996. Sensory testing methods. ASTM Manual Series, MNL 26. ASTM International, West Conshohocken, PA.

Chervin, C. 1992. Reduction of wound-induced respiration and ethylene production in carrot root tissues by gamma irradiation. Postharvest Biol. Technol. 2:7-17.

Cruz, J.N., C.A. Soares, A.D.T. Fabbri, B.R. Cordenunsi, and S.F. Sabato. 2012. Effect of quarantine treatments on the carbohydrate and organic acid content of mangoes (cv. Tommy Atkins). Radiat. Phys. Chem. 81:1059-1063.

Delgado-Vargas, F. 2003. Natural colorants for food and nutraceutical uses. CRC Press, Boca Raton, FL.

Dong, C.Z., J.L. Montillet, and C. Triantaphylides. 1994. Effects of gamma-irradiation on the plasma-membrane of suspension-cultured apple cells-Rapid irreversible inhibition of $\mathrm{H}^{+}-$ ATPase activity. Physiol. Plant. 90:307-312.

Drake, S.R., L.G. Neven, and P.G. Sanderson. 2003. Carbohydrate concentrations of apples and pears as influenced by irradiation as a quarantine treatment. J. Food Process. Pres. 27:165-172.

Drake, S.R., P.G. Sanderson, and L.G. Neven. 1999. Response of apple and winter pear fruit quality to irradiation as a quarantine treatment. J. Food Process. Pres. 23:203-216.

Environmental Protection Agency. 2014. The phaseout of methyl bromide. In: Ozone layer protection-Regulatory program. Washington, DC. 5 Aug. 2014. <http://www.epa.gov/ozone/ $\mathrm{mbr} / \mathrm{index} \cdot \mathrm{html}>$

Fan, X.T. and D.W. Thayer. 2001. Quality of irradiated alfalfa sprouts. J. Food Prot. 64:1574-1578.

Food and Drug Administration. 2011. Code of federal regulations title 21 , volume 3 . U.S. Department of Health and Human Services, Washington, DC. 21 June 2012. <http://www. accessdata.fda.gov/scripts/cdrh/cfdocs/cfcfr/ CFRSearch.cfm?CFRPart $=179 \&$ showFR $=1 \&$ subpartNode $=21: 3 \cdot 0.1 \cdot 1 \cdot 10.2>$

Gunes, G., C.B. Watkins, and J.H. Hotchkiss. 2000. Effects of irradiation on respiration and ethylene production of apple slices. J. Sci. Food Agr. 80:1169-1175.

Hallman, G.J. 2011. Phytosanitary applications of irradiation. Compr. Rev. Food Sci. Food Safety 10:143-151

Hamid, N.A., E.A. El-Dawla, and I.S. Nasr. 2012. Effects of shrink film wrapping and irradiation on storage quality of Leconte pears (Pyrus communis L.). J. Hort. Sci. Orn. Plants 4:169-176.

Hussain, P.R., R.S. Meena, M.A. Dar, and A.M. Wani. 2008. Studies on enhancing the keeping quality of peach (Prunus persica Bausch) cv. Elberta by gamma-irradiation. Radiat. Phys. Chem. 77:473-481.

Hussain, P.R., R.S. Meena, M.A. Dar, and A.M. Wani. 2010. Carboxymethyl cellulose coating and low-dose gamma irradiation improves storage quality and shelf life of pear (Pyrus communis L., cv. Bartlett/William). J. Food Sci. 75:M586-M596.

Lawless, H.T. and H. Heymann. 2010. Sensory evaluation of food: Principles and practices. 2nd Ed. Springer, New York, NY.

Lester, G.E. and B.D. Whitaker. 1996. Gamma-rayinduced changes in hypodermal mesocarp tissue plasma membrane of pre- and post-storage muskmelon. Physiol. Plant. 98:265-270.

Massey, L.M., Jr. 1964. Some effects of gamma radiation on the keeping quality of apples. J. Agr. Food Chem. 12:268-274.

Maxie, E.C., N.F. Sommer, J.M. Carlos, and L.R. Henry. 1966. Effect of gamma radiation on the 
ripening of Bartlett pears. Plant Physiol. 41:437-442.

McDonald, H., M. McCulloch, F. Caporaso, I. Winborne, M. Oubichon, C. Rakovski, and A. Prakash. 2012. Commercial scale irradiation for insect disinfestation preserves peach quality. Radiat. Phys. Chem. 81:697-704.

Methyl Bromide Technical Options Committee. 2011. Montreal protocol on substances that deplete the ozone layer. In: 2010 Report of the Methyl Bromide Technical Options Committee. p. 395. United Nations Environmental Programme (UNEP).

Miller, R.B. 2005. Electronic irradiation of foods: An introduction to the technology. Springer, New York, NY.

Mitcham, E.J., C.H. Crisosto, and A.A. Kader. 1996. Pear, Bartlett: Recommendations for maintaining postharvest quality. In: Perishables handling \#86. 31 July 2013. <http://postharvest.ucdavis. edu/PFfruits/PearBartlett/>.

Nielsen, S.S. 2010. Food analysis laboratory manual. 2nd Ed. Springer Science+Business Media, LLC, New York, NY.
Peryam, D.R. and F.J. Pilgrim. 1957. Hedonic scale method of measuring food preferences. Food Tech. (Sept.):9-14.

R Development Core Team. 2011. R: A language and environment for statistical computing. $\mathrm{R}$ Foundation for Statistical Computing. Vienna, Austria. 3 Apr. 2013. <http://www.R-project. org/>.

Rothman, L. and M.J. Parker. 2009. Just-aboutright scale design, usage, benefits, and risks. ASTM Manual MNL63. ASTM International, Conshohocken, PA.

Saltveit, M.E. 2012. Measuring respiration. Postharvest biology and technology (PLS 172) lecture handout. University of California, Davis, CA. 23 Aug. 2012.<http://ucce.ucdavis. edu/files/datastore/234-20.pdf > .

Stanley, J.K. 1991. Post-harvest physiology of perishable plant products. In: Post-harvest physiology of perishable plant products B2-Post-harvest physiology of perishable plant products. Van Nostrand Reinhold, New York, NY.
Stone, H. and J. Sidel. 2004. Sensory evaluation practices. 3rd Ed. Elsevier Academic, San Diego, CA.

U.S. Department of Agriculture. 2013. National statistics for pears. In: Pears, Bartlett-Production, measured in tons. National Agricultural Statistics Service, Washington, DC. 7 Apr. 2013. <http:// www.nass.usda.gov/Statistics_by_Subject/result. php?3AA6758B-C347-339E-AB1B-2D97B805 CCC0\&sector $=$ CROPS\&group $=$ FRUIT $\% 20 \%$ 26\%20TREE\%20NUTS\&comm $=$ PEARS $>$.

U.S. Department of Agriculture-Animal and Plant Health Inspection Service-Plant Protection and Quarantine. 2013. Treatment manual. Washington, DC. 2013 May 17. <http://www.aphis. usda.gov/import_export/plants/manuals/ports/ downloads/treatment.pdf $>$.

Wani, A.M., P.R. Hussain, R.S. Meena, and M.A Dar. 2008. Effect of gamma-irradiation and refrigerated storage on the improvement of quality and shelf life of pear (Pyrus communis L., cv. Bartlett/William). Radiat. Phys. Chem. 77:983-989. 